\title{
SOAP in Practice: Learning Outcomes of a Cross- Institutional Innovation Project Conducted by Teachers, Student Teachers, and Teacher Educators
}

Citation for published version (APA):

Seezink, A., Poell, R., \& Kirschner, P. A. (2010). SOAP in Practice: Learning Outcomes of a Cross-Institutional Innovation Project Conducted by Teachers, Student Teachers, and Teacher Educators. European Journal of Teacher Education, 33(3), 229-243. https://doi.org/10.1080/02619768.2010.490911

DOI:

10.1080/02619768.2010.490911

Document status and date:

Published: 01/08/2010

Document Version:

Peer reviewed version

Document license:

CC BY-SA

Please check the document version of this publication:

- A submitted manuscript is the version of the article upon submission and before peer-review. There can be important differences between the submitted version and the official published version of record. People interested in the research are advised to contact the author for the final version of the publication, or visit the DOI to the publisher's website.

- The final author version and the galley proof are versions of the publication after peer review.

- The final published version features the final layout of the paper including the volume, issue and page numbers.

Link to publication

\section{General rights}

Copyright and moral rights for the publications made accessible in the public portal are retained by the authors and/or other copyright owners and it is a condition of accessing publications that users recognise and abide by the legal requirements associated with these rights.

- Users may download and print one copy of any publication from the public portal for the purpose of private study or research.

- You may not further distribute the material or use it for any profit-making activity or commercial gain

- You may freely distribute the URL identifying the publication in the public portal.

If the publication is distributed under the terms of Article $25 \mathrm{fa}$ of the Dutch Copyright Act, indicated by the "Taverne" license above, please follow below link for the End User Agreement:

https://www.ou.nl/taverne-agreement

Take down policy

If you believe that this document breaches copyright please contact us at:

pure-support@ou.nl

providing details and we will investigate your claim.

Downloaded from https://research.ou.nl/ on date: 26 Apr. 2023 
SOAP in Practice: Learning Outcomes of a Cross-Institutional

Innovation Project Conducted by Teachers, Student Teachers, and

\section{Teacher Educators}

Seezink, A. ${ }^{1}$, Poell, R. F. ${ }^{1}, \&$ Kirschner, P. A. ${ }^{2}$

${ }^{1}$ Department of Human Resource Studies, Tilburg University, Tilburg, The Netherlands

${ }^{2}$ Netherland Laboratory for Lifelong Learning (NeLLL), Open University of the Netherlands, Heerlen, The Netherlands

A. (Audrey) Seezink (corresponding author):

Tilburg University

Department of Human Resource Studies

P.O. Box 90153

5000 LE Tilburg

The Netherlands

Phone: +31 134662499

Fax: +31 134663002

E-mail: A.Janssen-Seezink@uvt.nl

R.F. (Rob) Poell

Department of Human Resource Studies

Tilburg University

PO Box 90153

5000 LE Tilburg

The Netherlands

P.A. (Paul) Kirschner

Netherland Laboratory for Lifelong Learning (NeLLL)

Open University of the Netherlands

PO Box 2960

6401 DL Heerlen

The Netherlands 


\section{SOAP in Practice: Learning Outcomes of a Cross-Institutional Innovation Project Conducted by Teachers, Student Teachers, and \\ Teacher Educators}

This paper reports on a case study investigating learning outcomes at the individual and organizational level of a cross-institutional innovation project based on the SOAP

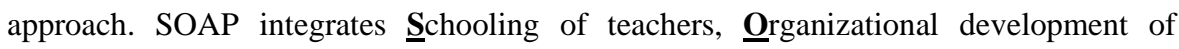

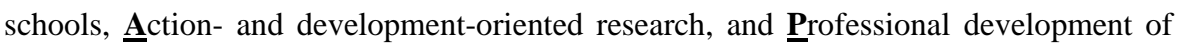
teachers. The innovation project was aimed at combining teachers, student teachers, and teacher educators in an alliance to design and develop new competence-based vocational educational arrangements for pupils. An inductive qualitative analysis of 37 semistructured interviews among the participants revealed seven main categories of individual learning outcomes: attitudes, project design and management, collaboration, action theory, teaching practice, educational principles, and developments within secondary vocational education. Three main categories of organizational learning outcomes were identified: institution-level learning, project-level learning, and combining institution-level and project-level learning. A tension was identified between the participants' individual interests in learning and personal development, and, the need for organizational learning aimed at improving organizational processes.

Keywords: individual learning outcomes, organizational learning outcomes, competence-based vocational education, teacher education

In recent years, schools in Dutch secondary education have been confronted with several large-scale educational reforms initiated by the government. Research into school restructuring and educational change shows that large-scale reforms often elicit concerns, doubts, and resistance to change among teaching staff (e.g., Geijsel, 2001; Hargreaves, 2005; Van Eekelen, 2005). Teachers involved in educational reforms are expected to change their ways of teaching, undertake new teaching activities, and give new meaning to their role as 
teacher. As a result, the views, beliefs, values, and attitudes of these teachers need to be reassessed (Seezink, Poell, \& Kirschner, 2009).

Rowan $(1990$; 1995) proposed a commitment strategy to educational reforms focusing on supporting teachers' decision making and enhancing teacher engagement as a tool for improving teaching quality and student achievements. According to Smith and Rowley (2005), adopting a commitment strategy enables schools to be more successful in professional teacher development and obtain greater stability in the teaching staff. In order to reduce anxiety and resistance among teaching staff, It is important to not only take into account the objective characteristics of the educational reform but also the manner in which those involved attach significance to it (Geijsel, 2001).

The growing emphasis on school development associated with educational reform causes a renewed interest in teachers' competences and professional identities. Traditional approaches to teacher training are have been characterized as irrelevant for preparing teachers for every-day teaching practice and, hence, in need of radical restructuring (Korthagen, Loughran, \& Russell, 2006). To this end, schools are paying increased attention to and becoming increasingly involved in initial teacher education in addition to their work in professional development programs. New collaborations have been initiated among schools, teacher-training institutes, and universities to examine opportunities for linking theory and practice, for example, by enabling student teachers to participate in innovative projects to fulfill their practice-period requirements.

\section{Individual and Organizational Learning}

Viewed from a conceptual perspective, these collaborations are aimed at connecting individual and organizational learning. Individual learning is defined as "an ongoing workrelated process of undertaking activities that leads to change in cognition or behavior, or both” (Meirink, 2007, p. 19) including becoming aware of one’s implicit views and beliefs

(Berings, 2006). The process of organizational learning is defined by Argyris and Schön (1996) as acquiring, processing, and storing information at the collective level. "Generally an 
organization may be said to learn when it acquires information (knowledge, understanding, know-how, techniques or practices) of any kind and by whatever means. (...) The generic schema of organizational learning includes some informational content, a learning product; a learning process which consists in acquiring, processing and storing information; and a learner to whom the learning process is attributed” (Argyris \& Schön, 1996, p. 3).

The importance of individual learning for organizational learning is widely recognized (e.g., Casey, 2005; Crossan, Lane, \& White, 1999; Forman, 2004). Organizational learning cannot occur without individual learning. At the same time, however, organizational learning is seen as being more than simply an accumulation of individual learning experiences (Casey, 2005). Individual learning is considered a necessary but insufficient precondition for organizational learning. Organizational learning is considered to have occurred when a product of collective activity has been embodied in the systems, policies, or culture of the organization (Argyris \& Schön, 1996).

\section{The SOAP Approach}

In an attempt to promote individual and organizational learning, a number of Dutch schools have been experimenting with giving already qualified teachers the responsibility for restructuring educational programs into new competence-based vocational curricula. Van der Sanden (2004) emphasized the importance of creating strong regional knowledge communities to link individual learning with organizational learning in schools. This article reports on a case study investigating the learning outcomes of a cross-institutional innovation

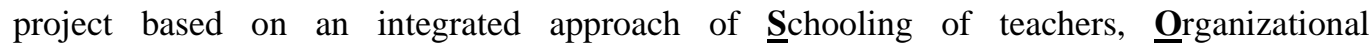
development (of schools and teacher-training institutes), Action and development oriented research, and Professional development of teachers; in short, the SOAP approach (Seezink \& Van der Sanden, 2005). The creation of knowledge communities inspired by the SOAP approach is aimed at integrating these four practices. Establishing better exchanges among employees of educational institutes (e.g., student teachers, educational researchers, teachers, and teacher educators) brings new opportunities for linking individual learning with 
organizational learning in schools (Seezink \& Van der Sanden, 2005). A number of Dutch schools have been experimenting with the SOAP approach, bringing together teachers, student teachers, and teacher educators in an alliance to design and develop new competencebased educational arrangements for pupils. In the Netherlands, school policies and actions in the fields of teacher schooling, development of schools as work organizations, educational research, and professionalization of teachers are usually considered different tasks, undertaken by different actors, with different perspectives, employed at different institutions.

Teachers currently employed in vocational education are expected to change their teaching practice towards competence-based education. In this move, teachers are becoming increasingly involved in designing and developing competence-based curricula (Seezink, Poell, \& Kirschner, 2009). Teachers are now expected to devise their own programs and play active roles in their schools' organizational development instead of simply delivering instructional programs provided by educational publishers.

\section{Knowledge Communities and Expansive Learning}

A key tenet of the SOAP approach is the establishment of knowledge communities, consisting of multidisciplinary teaching staff aiming to create and implement innovative educational practices that contribute to school development (Seezink \& Van der Sanden, 2005). The SOAP approach is thus in line with the commitment strategy to educational reforms advocated by Rowan (1990, 1995). In order to facilitate knowledge communities, organizational and individual personal and professional development need to become major issues in school policies.

In establishing knowledge communities, school organizations combine individual and organizational learning processes with a view to promoting 'expansive learning' (TuomiGröhn \& Engeström, 2003). To generate expansive learning, a group of individuals involved in collective activity needs to question existing practices, initiating debate and analysis of contradictions which leads to the collaborative development of new and complex communal concepts and ideas. Resolving the contradictions may result in an alternative model. The latter 
needs to be examined and its implications explored prior to the implementation process. Subsequently a proliferation and consolidation process needs to occur and, finally, a reflective evaluation process needs to take place in order to create an expansive learning cycle (TuomiGröhn \& Engeström, 2003).

\section{Outcomes of SOAP-Inspired Knowledge Communities}

Creating knowledge communities according to the SOAP approach and promoting expansive learning among the participants can lead to both individual learning and organizational learning. Knowledge communities in the context of innovation projects can facilitate not only continuing professional development of teaching staff, but also knowledge flows across different levels of the organization (Casey, 2005). These knowledge flows are a crucial factor in the educational reform towards competence-based education which requires many changes on the organizational level, including alternative educational methods, new approaches to assessment, changes in the classroom, teaching staff empowerment, and so forth. Individual learning and organizational learning, therefore, need to go hand in hand.

Establishing knowledge communities of teachers, teacher educators, and student teachers has many potential advantages. First, the communities may contribute to a shared professional culture, creating better mutual understanding. A sustained change in teaching practice involves individual learning and organizational learning; therefore, it is important to create a culture supportive of educational reform that can facilitate individual change efforts (Knapp, 1997). Second, by engaging in joint professional development, teachers may be able to better transfer their learning experiences to other aspects of their instructional context (e.g., developing new educational programs), again bridging individual learning and organizational learning. Third, by introducing student teachers into innovation projects the student teachers gain a broader and better view of the teaching profession. Finally, by maintaining close contact with teachers, teacher educators are better able to keep the professional development programs they offer up to date. 


\section{Problem Statement and Research Question}

This study aims to contribute to further scientific knowledge about workplace learning by teaching staff within the scope of educational innovations, providing insight into the learning outcomes of knowledge communities, and more specifically into collaborations based on partnerships among educational institutes. Research on knowledge communities, communities of practice, and communities of learners has focused primarily on formation and sustainability issues (e.g., Akkerman, Petter, \& De Laat, 2008; Dooner, Mandzuk, \& Clifton, 2008; Erickson, Minnes Brandes, Mitchell, \& Mitchell, 2005) or on the roles of these communities in facilitating learning processes (e.g., Boud \& Middleton, 2003; Klein, Connell, \& Meyer, 2005; Ten Dam \& Blom, 2006). Empirical research into individual or organizational learning outcomes of knowledge communities, however, remains scarce (see Mittendorff, Geijsel, Hoeve, De Laat, \& Nieuwenhuis, 2006 for an exception). This study, therefore, focuses on the following research question: What learning outcomes can be identified, both at the individual and organizational levels, of implementing a SOAP-inspired innovation project?

\section{Methods}

\section{Participants}

In the Netherlands there are different types of vocational education. After primary school, about $60 \%$ of the pupils (ages 12-15) leaving primary education attend prevocational secondary education (PVSE; in Dutch: VMBO). Upon completion of PVSE, they (ages 1518) enter senior secondary vocational education (SSVE; in Dutch MBO), where they obtain their vocational qualification. The participants in the innovation project are student teachers, teachers working in PVSE schools, teachers working in SSVE schools, and teacher educators. The participants collaborated in knowledge communities aimed at developing competencebased educational materials which were, subsequently, to be used in the context of their own

school environments. There were 37 participants in the study (21 male, 16 female). The 
participants had different backgrounds and worked within inter- and intra-institutional arrangements (i.e., different PVSE schools, one SSVE school, and a teacher trainer institute). Of the participants, 11 were student teachers, 15 were teachers working in PVSE schools, 4 were teachers working in SSVE schools, and 7 were teacher educators at eight different institutions (six PVSE schools, one SSVE school, and one teacher-training institute).

\section{Data Collection}

Semi-structured interviews were held with all participants. The protocol for these semistructured interviews included general questions (e.g., age, employment, teaching experience) and more specific questions about the innovation project that they were working on, their professional development activities, and the outcomes of the project. Sample questions are: "How would you characterize the innovation you are working on?", "How did you get involved in this innovation?”, "What did you learn from participating in the project?” and "What difficulties did you encounter during the project and how were they resolved?"

\section{Procedure}

Participants were approached by the management of the innovation project to participate in the study. During one of the regular meetings of the innovation project, the researchers gave a 20-minute presentation in which they informed the participants about the contours of the study. During this session the participants could ask questions or make remarks about the study. Subsequently, the researchers made arrangements with the participants for the interviews which took place from April through June 2007 in secluded areas in the school buildings where the teachers were employed. Two interviewers were randomly assigned to interviews with the participants. The interviews were recorded with informed consent on a digital voice recorder and were later transcribed for analysis.

\section{Analysis}


Data analysis was performed using a grounded theory approach. First, the data was coded in an 'open coding' way, which means that the interviews were coded without pre-existing coding schemes; however, all relevant quotes concerning aspects of 'individual learning' and/or 'organizational learning' were coded. Through constant comparison of emerging codes, open coding gradually revealed a number of key dimensions which were then used to analyze the interviews in an iterative way. Next, these dimensions were interconnected in categories through 'axial coding'. Finally, 'selective coding' was carried out to reduce redundant information and maintain the most relevant and related codes for the research question (Glaser, 2004).

During the analysis of the 'individual learning' construct, a distinction was made between professional development activities and learning outcomes. If teachers indicated they had learned something by carrying out a specific activity without making explicit what their learning outcome was, this was coded as a professional development activity. If teachers elaborated on the content of what they had learned such as certain activities, events, or processes, this was coded as a learning outcome. As the current research project's main interest was in learning outcomes, the professional development activities were not further explored in this study.

\section{Results}

A grounded-theory analysis of the interviews revealed seven different kinds of individual learning outcomes (84 quotes across 32 subjects) and three different kinds of organizational learning outcomes (46 quotes across 26 subjects). The seven main categories of individual learning outcomes are: attitudes, project design and management, collaboration, action theory, teaching practice, educational principles, and, finally, developments within secondary vocational education. The three different main categories of organizational learning outcomes are: institution-level learning, project-level learning, and combining institution-level and 
project-level learning. Table 1 contains the main findings regarding individual learning outcomes. Table 2 contains the main findings of organizational learning outcomes.

\section{$<<<$ Insert Table 1 about here $>>>$}

\section{Individual Learning Outcomes}

Attitudes. Within the first category of individual learning outcomes, participants revealed that they had become more aware of their own work attitudes. This category contains 11 quotations across nine subjects. Four sub-categories were identified: self confidence, openness to change, insight in strengths and weaknesses, and critical work attitude. Three participants mentioned an increase in self confidence (subjects 1, 2, 20), expressing feeling more secure about job content, about their functioning as a teacher, and about undertaking new ventures. Four participants $(7,20,30,37)$ mentioned being more open-minded about change as a result of the innovation project. Two participants $(23,25)$ claimed to have gained a better insight in their own strengths and weaknesses, for example, an increased awareness of their own teaching habits. One participant (5) talked about the development of a more critical work attitude and an increased willingness to question one's viewpoints. The following quotation illustrates the development of a critical work attitude:

"I think that I...by undertaking all of these internships and the connections between theory and practice get a sense of what is usable and what is not, or how you have to do this differently or that I get a clear view of things and am critical at the same time. [...] Yes, what's in it for me, is it a good assignment and was it thought thorough, well so a critical view. I think that, that is my gain”

(Subject nr 5, student teacher, Individual learning outcomes - Attitudes)

Project Design and Management. The second category of individual learning outcomes deals with participants gaining insight in the organization of the innovation project. This category consists of 13 quotes across 12 subjects. Two sub-categories were identified: 
project design and project management. The six participants making up the first sub-category $(21,23,27,28,30,32)$ reported learning about the design process of the innovation project, for example, that they require a large investment of time, effort, and energy. The seven participants in the second sub-category $(9,22,23,24,25,26,29)$ indicated having learned about the management of the innovation project (e.g., in terms of decision making, scheduling, and implementation of the project). The following quotation illustrates an insight in managing the project:

"Yes, it is, eh, very important to, eh make a very liberal planning for example, a very liberal planning. You have to try, eh, you cannot always assess this in advance, try to involve the right people.”

(Subject nr 22, PVSE teacher, Individual learning outcomes - Project design and management)

Collaboration. Within the third category of individual learning outcomes, participants revealed gaining insight in collaboration processes. This category consists of 16 quotes across eight subjects. Three sub-categories of collaboration were identified: with individuals, with companies, and with educational institutes. Six participants $(5,12,24,29,34,35)$ indicated that by had learned about collaborating with individuals, for example, how to discuss ideas, articulate arguments, react to feedback of others, and collaborate in a constructive way. Five (7, 22, 29, 32, 35) claimed having learned about collaboration with companies, for instance, about the different cultures between schools and companies and how to bridge the gap, and about the commitment of companies to contribute to the out-of-school education of pupils. One participant (29) mentioned gaining insight about the collaboration with educational institutes, especially about the curriculum for new teachers. The following quotation illustrates learning about collaboration with companies:

"So immediately [we went] to companies to secure the collaboration, because we think the sooner we secure this, the greater the chance of success. [...] And companies, they put this aside because this will start only after six months. [...] And then we think: these companies 
do not take into account that these projects need to go to the publisher one month ahead and then the teachers they need to prepare, and, yes, so [...] companies do not see that. Like, we are not aware of other things in companies. These are two completely different cultures and through these meetings we came closer to each other.”

(Subject nr 29, PVSE teacher, Individual learning outcomes - Collaboration)

Action Theory. The fourth category of individual learning outcomes deals with participants gaining insight in the contents of their own views and beliefs about education. This category contains 16 quotes across 12 subjects. Three sub-categories were identified: making one's action theory explicit, changing one's action theory, and confirming one's action theory. Seven participants $(13,28,29,30,31,32,36)$ indicated that participating in an innovation project made their viewpoints explicit about various elements of education, such as contents and sequence of curricula, teaching in general, pedagogy, learning of pupils, and so forth. The four subjects making up the second sub-category $(6,14,27,29)$ claimed that participating in the innovation project had changed aspects of their own action theories about various elements of education. Two participants $(12,34)$ mentioned that their participation had confirmed their existing action theories. The following quotation illustrates a change in action theory about education:

“To begin with what I said earlier, well, you have some kind of ideal image. For example, normally I have a sequence in which several concepts follow each other and there is a certain structure in that content and now you take on a project. The new insight is that you perhaps need to let go of that, even if you find out that it is not possible to let it go entirely. Initially I also really thought that it did not matter, we are making nice education programs, full of context and that is motivating. But you can find out that there still needs to be learned something. Certain concepts are not transferable without the basics.”

(Subject nr 6, teacher educator, Individual learning outcomes - Action theory)

Teaching Practice. Within the fifth category of individual learning outcomes, participants claimed to have gained a broader view of the professional practice of teaching. 
This category contains 16 quotations across 13 subjects. Three sub-categories were identified: pedagogy, dealing with pupils, and the teaching profession. Five participants $(5,9,12,20,24)$ said they had learned about pedagogical issues, for example, designing, experiencing and/or observing (alternative) pedagogies. Four participants $(1,18,22,37)$ mentioned learning about characteristics of pupils, building teaching relationships, and alternative ways of guiding pupils. Five participants $(1,3,8,10,14)$ talked about discovering new aspects of the teaching profession, for example, about teaching other subjects, teaching other levels of education or schools, and difficulties inherent to the teaching profession. The following quotation illustrates learning about the teaching profession:

“I have gained a better, broader view; by exchanging experiences you'll get a broader view.

Broader also than when you just teach, then I teach only one subject. So yes, you gain a much broader view."

(Subject nr 14, teacher educator, Individual learning outcomes - Teaching practice)

Educational Principles. The sixth category of individual learning outcomes refers to participants claiming to have learned, and sometimes to still be in the process of learning, about underlying educational principles. This category contains nine quotes across eight subjects. Two sub-categories were identified: empowering pupils and embedding education in authentic environments. The four participants making up the first sub-category $(1,19,22,35)$, mentioned questioning themselves about how to empower pupils, for example, how to trigger a professional attitude in them. The five participants in the second sub-category $(7,8,19,29$, 34) said they had learned how to reconnect the learning-program contents with meaningful learning experiences by taking into account new educational principles. The following quotation illustrates learning about empowering pupils:

"Yes, well, that there is real room for thinking about what you are actually doing during teaching, that you really try to investigate how pupils acquire knowledge, how to motivate them, how to tempt them into learning.” 
(Subject $\mathrm{nr}$ 8, SSVE teacher, Individual learning outcomes - Educational principles)

Developments in Secondary Vocational Education. Within the seventh category of individual learning, three participants $(4,18,30)$ claimed to have learned about the educational reforms and current developments within secondary vocational education. This category contains four quotes across three subjects. The following quotation illustrates learning about developments in secondary vocational education:

"For me, it was a really good way to clarify for myself which development questions SSVE and PVSE schools have at the moment, in as far as they are involved in competence-based education.”

(Subject nr 4, teacher educator, Individual learning outcomes - Developments in secondary vocational education)

\section{$<<<$ Insert Table 2 about here $>>>$}

\section{Organizational Learning Outcomes}

Institution-Level Learning. The first main category concerns organizational learning at the level of separate institutions and contains 12 quotes across eight subjects. Two subcategories were identified: quality improvement and rearranging teacher-training curricula. The four participants in the first sub-category $(1,8,21,34)$ indicated that accreditation visits (by both internal and external committees) served as a quality check and sometimes even led to measures to improve the quality of education. The four subjects making up the second subcategory $(4,6,17,23)$ mentioned gaining a better view of developments within vocational education and using these insights as input for rearranging teacher-training curricula. The following quotation illustrates rearranging teacher-training curricula:

"The project itself started as a way for the teacher-training institute to gain more insight in the current processes within PVSE and SSVE schools. [...] Later, well, maybe that did not happen later, but our 
experience is that the project itself broadened to the teacher-training institute. And now it's used as a tool to make changes in our curricula. [...] And for the teacher-training institute as a whole, it's in my opinion very good to have close contacts with some other qualification programs in PVSE and SSVE, so that we can align our own programs and deliver teachers to their requirements.”

(Subject $\mathrm{nr} 4$, teacher educator, Organizational learning outcomes - Institutionlevel learning)

Project-Level Learning. The second main category deals with organizational learning at the innovation-project level, among the various partners. It contains 19 quotations across 15 subjects. Two sub-categories were identified: emphasis on evaluation and project adjustment. The 12 participants in the first sub-category $(2,3,6,13,14,15,17,26,27,30,35,37)$ indicated that their participation in the innovation project enabled them to be more focused on evaluation. Regular teaching has a lot of short-term demands on (aspiring) teaching staff and, hence, they do not normally have the time, money, or energy to look at longer-term goals. The emphasis on evaluation within the innovation project provided them with more opportunities to think long term. The five participants making up the second sub-category (6, 13, 32, 34, 36) mentioned that evaluation within the innovation project led to structural changes being implemented. Adjustments were made to the project along the way based on formative evaluations. The following quotation illustrates the emphasis on evaluation:

"Well it is nice to look at, well, does it work the way we do it? Does that go well? How come? So through this project you get the opportunity to look deeper into this. [...] One did go well, the other did not, but here you have the time to look what is the problem. Because if you just do your job you do not have time for these things.”

(Subject nr 2, SSVE teacher, Organizational learning outcomes - Project-level learning)

Combining Institution-Level and Project-Level Learning. The third main category concerns the transfer of knowledge from separate institutions to the project as well as vice versa. This category contains 13 quotes across 11 subjects. Three sub-categories were 
identified: project-to-institution transfer, institution-to-project transfer, and criticism raised. The seven participants making up the first sub-category $(7,21,22,26,28,34,35)$ talked about how the educational materials developed in the project for long-term use created a snowball effect by involving other local teachers. The five participants in the second subcategory $(3,11,19,29,35)$ claimed having become more aware of the opportunities for collaboration and the possible use of expertise available in their own institution with a view to aligning the partners within the innovation project. The seven participants in the third subcategory $(2,3,5,15,16,30,31)$ raised critical remarks about the innovative nature and sustainability of the innovation project. They expressed doubts about how innovative the project was and leveled concerns about being unable to sustain the results of the innovation project within their own institutes after it had ended. The following quotation illustrates institution-to-project transfer:

“Traditionally they [i.e., student teachers] do their internships within PVSE and the first years of preparation for polytechnics. Through the innovation project, SSVE has received more attention within the teacher-training institute. So, student teachers are more likely to choose SSVE for their internships.”

(Subject $\mathrm{nr}$ 3, SSVE teacher, Organizational learning outcomes - Combining inst/proj learning)

\section{Conclusions and Discussion}

The aim of this study was to contribute to further scientific knowledge about workplace learning by teaching staff within the scope of educational innovation projects, more specifically to investigate the individual and organizational learning outcomes of SOAPinspired knowledge communities based on partnerships among educational institutes. From semi-structured interviews with 37 participants we can conclude that they valued the collaboration as well as the inter- and intra-institutional nature of the innovation project, which led to many reported instances of individual and organizational learning. 
At the individual level, participants seem to have learned most about project design and management, about their own action theories with regard to education, and about the professional practice of teaching. At the organizational level, most learning seems to have occurred at the project level (among partners), although many instances were also reported of institute-level learning outcomes and in the interface between the project and the various separate institutions.

All participants, from all of the different backgrounds (student teachers, teachers, teacher educators) reported having gained a broader view of the teaching profession and the difficulties associated with their different backgrounds. The gradual enculturation of student teachers within professional teaching practice was especially valued by participants from all backgrounds. The shared responsibility for the innovation project in combination with the expertise of teachers and teacher educators seemed to provide the necessary precondition for their legitimate peripheral participation (Lave \& Wenger, 1991).

Meirink (2007), eho studied individual teacher learning in collaborative settings, found that many experienced teachers changed their beliefs when the learning was embedded in interdisciplinary teams over a sustained period. She concluded that initiatives aimed at teacher development over longer time periods in the context of a project were relatively successful in changing teachers' beliefs about education. Our findings are in line with these conclusions. We also see support from our analysis for Rowan's (1990; 1995) plea for a commitment strategy to educational reforms, as the SOAP approach used in the innovation project emphasized commitment from all those involved.

Van Woerkom (2003) identified a tension betweenindividual orientations and behavior on the one hand, and organizational learning outcomes aimed at improving productivity on the other. Where individuals may undertake certain activities in their own interest, those activities may be viewed by the organization as an instrument for change. The critical remarks made by participants in this study about the transfer and/or the possible lack thereof between the innovation project and their schools also revealed a tension between individual interest in learning and personal development on the one hand, and organizational 
learning aimed at improving organizational processes on the other. Some participants in the study also reported individual learning outcomes that they felt were outside of the scope of the innovation project. By making such learning outcomes explicit and discussing them with others, they can be evaluated by the participants for an optional implementation process (i.e., expansive learning). Identifying and discussing these learning outcomes, thus, become preconditions for organizational learning. A focus for further research can be found in the management of this process. Overall, however, the SOAP approach did seem to offer teachers as well as educational institutions good opportunities for linking individual and organizational learning.

One underlying assumption in undertaking this cross-institutional innovation project was that by including several educators from different institutions, this initiative would generate a snowball effect. However, this case study showed that learning outcomes related to transfer (between institutions and project) caused some difficulties. Some teachers reported experiencing resistance within their own institutions, both at the teacher level and at the management level, both in finding support for participation and in the internal communication about the results. Often school management focused on formalized ways of professional development (i.e., attending courses, workshops or similar events), whereas teachers preferred to learn in the workplace by interacting with the SOAP partners in the innovation project which was directly relevant for their work. Formal training does not seem overly effective and tends to impede the transfer of learning from course settings to workplace settings (Knight, 2002; Poell, 1998).

The evaluation aspect of innovation projects, and also of teaching in general, remains a difficult issue. Since evaluation can be fully addressed only after the implementation of the project, it is not often a key focus and therefore subject to omission. Even though evaluation was often mentioned as a motive for participating in the innovation project, it seems to have no priority in the minds of the participants. Similar to regular teaching practice, short-term goals such as, keeping up teaching performance and finishing the project in time seem to be more prominent than long-term goals such as, improvement, evaluation, and organizational 
learning. The management of such innovation projects needs to clarify the crucial relevance of evaluation and emphasize recurrently the need for a thorough evaluation of the project.

An implication for the field of teacher education is that initial teacher education should not be isolated, but should look for partnerships with other educational institutes. This case study is an example of how these partnerships can take form and what they can contribute. These partnerships appear to lead to positive learning outcomes for the involved participants, while also creating a broader view and more mutual understanding for both the challenges faced by initial teacher training institutes and competences required for and the problems associated with continuing professional development trajectories. Creating networks based on SOAP-principles for creating these cross-institutional innovation projects is, thus, recommended.

In terms of limitations that need to be taken into account, determining all relevant learning outcomes was a challenge in this study, since learning can operate at several conscious and unconscious levels. By interviewing participants about their experiences, we gained access only to their conscious -- and possibly deliberate -- learning outcomes. We defined individual learning as an ongoing work-related process leading to changes in cognition, behavior, or both, including the aspect of becoming aware of one's implicit views and beliefs (Berings, 2006; Meirink, 2007). Although implicit learning tends to work at the unconscious level, we were able to identify individual learning outcomes related to participants' attitudes and action theories, amongst other more explicit outcomes. Therefore, an appropriate method seems to have been used for gaining insight in implicit learning processes as well, although perhaps additional qualitative methods are desirable for exploring them more thoroughly in future studies.

All in all, creating cross-institutional knowledge communities based on the SOAP approach has been shown to involve educators in conceptualizing and designing competencebased vocational education and to create a number of promising opportunities for combining individual and organizational learning outcomes. 
Table 1. Main Findings from the Study: Individual Learning Outcomes.

\begin{tabular}{lll}
\hline Individual Learning Outcomes & $\begin{array}{l}\mathbf{8 4} \text { quotes / } 32 \\
\text { subjects }\end{array}$ \\
\hline Attitudes & Self confidence & -3 subjects \\
& Openness to change & -4 subjects \\
& Insight in strengths and weaknesses & -2 subjects \\
& Critical work attitude & -1 subject \\
\cline { 2 - 3 } & Total of quotes and subjects in category & 11 quotes / 9 subjects \\
\hline Project Design & Project design & -6 subjects \\
and Management & Project management & -7 subjects \\
\cline { 2 - 3 } & Total of quotes and subjects in category & 13 quotes / 12 subjects \\
\hline Collaboration & With individuals & -6 subjects \\
& With companies & -5 subjects \\
& With educational institutes & -1 subject \\
\cline { 2 - 3 } & Total of quotes and subjects in category & 16 quotes / 8 subjects \\
\hline Action Theory & Making one's action theory explicit & -7 subjects \\
& Changing one's action theory & -4 subjects \\
& Confirming one's action theory & -2 subjects \\
\cline { 2 - 3 } Total of quotes and subjects in category & 16 quotes / 12 subjects \\
\hline Teaching Practice & Didactics & -5 subjects \\
& Dealing with pupils & -4 subjects \\
& The teaching profession & -5 subjects \\
\cline { 2 - 3 } & Total of quotes and subjects in category & 16 quotes / 13 subjects \\
\hline Educational Principles & Empowering pupils & -4 subjects \\
& Embedding education in authentic & -5 subjects \\
environments & \\
\cline { 2 - 3 } Eecondary Vocational & Total of quotes and subjects in category & 9 quotes / 8 subjects \\
\hline & Total of quotes and subjects in category & 4 quotes / 3 subjects \\
& & \\
\hline & & \\
\hline & & \\
& &
\end{tabular}


Table 2. Main Findings from the Study: Organizational Learning Outcomes.

\begin{tabular}{lll}
\hline Organizational Learning & Outcomes & $\begin{array}{l}\text { 46 quotes / 26 } \\
\text { subjects }\end{array}$ \\
\hline Institution-Level & Quality improvement & -4 subjects \\
Learning & Rearranging teacher-training curricula & -4 subjects \\
\cline { 2 - 3 } & Total of quotes and subjects in category & 12 quotes / 8 subjects \\
\hline Project-Level Learning & $\begin{array}{l}\text { Emphasis on evaluation } \\
\text { Project adjustment }\end{array}$ & -12 subjects \\
\cline { 2 - 3 } & Total of quotes and subjects in category & 19 quotes / 15 subjects \\
\hline Combining Institution- & Project-to-institution transfer & -7 subjects \\
Level and & & \\
Project-Level Learning & Institution-to-project transfer & -5 subjects \\
& Criticism being raised & -7 subjects \\
\cline { 2 - 3 } & Total of quotes and subjects in category & 13 quotes / 11 subjects \\
\hline
\end{tabular}




\section{References}

Akkerman, S., Petter, C., \& De Laat, M. (2008). Organising communities-of-practice: facilitating emergence. Journal of Workplace Learning, 20, 383-399.

Argyris, C., \& Schön, D. A. (1996). Organizational learning II: Theory, method, and practice. Reading: Addison-Wesley.

Berings, M. (2006). On-the-job learning styles: Conceptualization and instrument development for the nursing profession. Doctoral Dissertation, Tilburg University, Tilburg, The Netherlands.

Boud, D., \& Middleton, H. (2003). Learning from others at work: Communities of practice and informal learning. Journal of Workplace Learning, 15, 194-202.

Casey, A. (2005). Enhancing individual and organizational learning: A sociological model. Management Learning, 36, 131-147.

Crossan, M. M., Lane, H. W., \& White, R. E. (1999). An organizational learning framework: From intuition to institution. Academy of Management Review, 24, 522-537.

Dooner, A., Mandzuk, D., \& Clifton, R. A. (2008). Stages of collaboration and the realities of professional learning communities. Teaching and Teacher Education, 24, 564-574.

Erickson, G., Minnes Brandes, G., Mitchell, I., \& Mitchell, J. (2005). Collaborative teacher learning: Findings from two professional development projects. Teaching and Teacher Education, 21, 787-798.

Forman, D. C. (2004). Changing perspectives from individual to organizational learning. Performance Improvement, 43, 16-21.

Geijsel, F. (2001). Schools and Innovations. Conditions fostering the implementation of educational innovations. Doctoral Dissertation, Radboud University Nijmegen, Nijmegen, The Netherlands.

Glaser, B. G. (2004). Naturalist inquiry and grounded theory. Forum: Qualitative Social Research, 5, 1-14. 
Hargreaves, A. (2005). Educational change takes ages: Life, career and generational factors in teachers' emotional responses to educational change. Teaching and Teacher Education, 21, 967-983.

Klein, J. H., Connell, N., \& Meyer, E. (2005). Knowledge charasteristics of communities of practice. Knowledge management research \& practice, 3, 106-114.

Knapp, M. S. (1997). Between systemic reforms and the mathematics and science classroom: The dynamics of innovation, implementation, and professional learning. Review of Educational Research, 67 227-266.

Knight, P. (2002). A systemic approach to professional development: Learning as practice. Teaching and Teacher Education, 18, 229-241.

Korthagen, F., Loughran, J., \& Russell, T. (2006). Developing fundamental principles for teacher education programs and practices. Teaching and Teacher Education, 22, 1020-1041.

Lave, J., \& Wenger, E. (1991). Situated learning: Legitimate peripheral participation. Cambridge, UK: Cambridge University Press.

Meirink, J. A. M. (2007). Individual teacher learning in a context of collaboration in teams. Doctoral dissertation: Leiden University.

Mittendorff, K., Geijsel, F., Hoeve, A., De Laat, M., \& Nieuwenhuis, A. F. M. (2006). Communities of practice as stimulating forces for collective learning. Journal of Workplace Learning, 18, 298-312.

Poell, R. F. (1998) Organizing work-related learning projects: A network approach. Doctoral Dissertation, Radboud University Nijmegen, Nijmegen, The Netherlands.

Rowan, B. (1990). Commitment and control: Alternative strategies for the organizational design of schools. Review of Reseach in Education, 16, 353-389.

Rowan, B. (1995). The organizational design of schools. In Bacharach, S. B. \& Mundell, B. (Eds.), Images of schools. Structures and roles in organizational behavior (pp. 1142). Thousand Oaks, CA: Corwin Press. 
Seezink, A., Poell, R. F., \& Kirschner, P. A. (2009). Teachers' individual action theories about competence-based education: The value of the cognitive apprenticeship model. Journal of Vocational Education \& Training, 61, 203-215.

Seezink, A., \& Van der Sanden, J. M. M. (2005). Lerend werken in de docentenwerkplaats: Praktijktheorieen van docenten over competentiegericht voorbereidend middelbaar beroepsonderwijs. [Learning and working within a teachers' workplace: Teachers' practical theories about competence oriented prevocational secondary education] Pedagogische Studiën, 82, 275-292.

Smith, T. M., \& Rowley, K. J. (2005). Enhancing commitment or tightening control: The function of teacher professional development in an era of accountability. Educational Policy, 19, 126-154.

Ten Dam, G. T. M., \& Blom, S. (2006). Learning through participation. The potential of school-based teacher education for developing a professional identity. Teaching and Teacher Education, 22, 647-660.

Tuomi-Gröhn, T., \& Engeström, Y. (2003). Conceptualising transfer: from standard notions to developmental perspectives. In Tuomi-Gröhn, T. \& Engeström, Y. (Eds.), Between school and work: new perspectives on transfer and boundary-crossing (pp. 19-38). Amsterdam, The Netherlands: Pergamon.

Van Eekelen, I. M. (2005). Teachers' will and way to learn: studies on how teachers learn and their willingness to do so. Doctoral Dissertation, Maastricht University, Maastricht, The Netherlands.

Van Woerkom, M. (2003). Critical reflection at work: Bridging individual and organizational learning. Doctoral Dissertation, Twente University, PrintPartners Ipskamp, Enschede, The Netherlands. 